\title{
Short Communication: Mechanism and Prevention of Irreversible Trapping of Atmospheric He During Mineral Crushing
}

\author{
Stephen E. Cox ${ }^{1,2}$, Hayden. B.D. Miller ${ }^{1,3}$, Florian Hofmann ${ }^{1,4}$, Kenneth A. Farley ${ }^{1}$ \\ ${ }^{1}$ Division of Geological and Planetary Sciences, California Institute of Technology, Pasadena, CA 91125, USA \\ $5 \quad{ }^{2}$ current address: Lamont-Doherty Earth Observatory, Columbia University, Palisades, NY 10964, USA \\ ${ }^{3}$ current address: Earth and Environmental Science Division, Los Alamos National Laboratory, Los Alamos, NM, 87545 USA \\ ${ }^{4}$ current address: Department of Earth Sciences, University of Southern California, Los Angeles, CA 90089, USA
}

Correspondence to: Stephen E. Cox (stephen@stephencoxgeology.com)

Abstract. A pervasive challenge in noble gas geochemistry is to ensure that analytical techniques do not modify the composition of the noble gases in the samples. Noble gases are present in the atmosphere and are used in a number of manufacturing procedures and by laboratory equipment. Of particular concern is the introduction of atmospheric or laboratory noble gases to samples during preparation before samples are placed in a vacuum chamber for analysis. Recent work has shown the potential for contamination of crushed samples with air-derived He that is not released by placing the samples under vacuum at low temperature. Using pure He gas as a tracer, we show that the act of crushing samples to a fine powder itself can introduce He contamination, but that this is easily avoided by crushing under liquid or in an inert atmosphere. Because the He is trapped during crushing, the same concern does not extend to samples that are naturally fine-grained when collected. The degree of He contamination even from crushing samples to sizes smaller than typically used for geochronology is insignificant for samples at least $1 \mathrm{Ma}$ and with more than $1 \mathrm{ppm} \mathrm{U}$ when the guidelines outlined here are followed.

\section{Introduction}

20 The five noble gases are reservoirs of important geochemical information, and the two stable isotopes of He have many uses for earth scientists. Geochemists measure rare ${ }^{3} \mathrm{He}$ (abundance $1.39 \times 10^{-6}$ of total $\mathrm{He}$ ) as a tracer of tritium in water, as a cosmogenic nuclide for surface exposure dating, as a tracer of mantle fluids, and as a synthetic tracer of experimental He degassing in minerals. The common isotope, ${ }^{4} \mathrm{He}$, is in turn a measure of temperature-dependent solubility in water, a radiogenic daughter product for thermochronology, and a signature of dust derived from crustal rocks. He gas is also used as an inert environment in various manufacturing processes and in laboratory cryogenics, sometimes in an isotopically purified form. There are no long-lived radioactive isotopes of $\mathrm{He}$, so a complication of these many uses is that, with only two isotopes, the system is always underdetermined relative to the number of potential components, and one must use additional contextual information or processing techniques to isolate the desired signal. Because of this omnipresent burden, we read the intriguing results of Protin et al. (2016) with some concern. 
https://doi.org/10.5194/gchron-2021-42

Preprint. Discussion started: 11 January 2022

(c) Author(s) 2022. CC BY 4.0 License.

(c) (i)
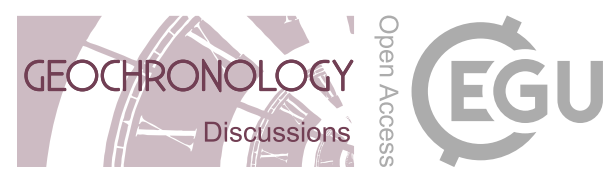

Protin et al. (2016) found that fine-grained minerals crushed in the laboratory before measurement appeared to irreversibly adsorb He from the atmosphere, meaning that the He would be adsorbed at room temperature and then retained until the sample was heated to high temperature during the measurement process. The idea that a sample might adsorb He at room temperature would not itself be cause for concern, as it is well known that surfaces can adsorb gas. However, this process is usually assumed

35 to be reversible, meaning that a sample placed in a vacuum chamber will relinquish the adsorbed air as readily as it was first adsorbed at room temperature or, to speed up the process, under a very mild heating compared to the temperatures used for sample gas extraction (for example, gentle heating to $50-150{ }^{\circ} \mathrm{C}$ prior to extraction at $>1000{ }^{\circ} \mathrm{C}$ is a common technique for cleaning noble gas samples). In contrast, Protin et al. found that the irreversibly trapped He was not released under vacuum during heating in a temperature range distinct from that in which the sample gas was released, which would render impossible distinguishing the two components without isotopic deconvolution.

The problem of trapped air in noble gas measurements is not a new one. In the Ar isotopic system commonly used for K/Ar and ${ }^{40} \mathrm{Ar} /{ }^{39} \mathrm{Ar}$ dating, an additional isotope can be used to correct for the pervasive air contamination caused by the high abundance of $\mathrm{Ar}$ in the atmosphere (approximately 1\%, compared to $5 \mathrm{ppm}$ for He), but this is usually not feasible with $\mathrm{He}$

45 due to the extremely low and relatively uncertain ${ }^{3} \mathrm{He} /{ }^{4} \mathrm{He}$ ratio of both air and radiogenic $\mathrm{He}$, and the potential for contamination with other sources of ${ }^{3} \mathrm{He}$ such as mantle-derived $\mathrm{He}$ and cosmogenic He. The ${ }^{3} \mathrm{He} /{ }^{4} \mathrm{He}$ ratio of air is usually assumed to be $1.39 \times 10^{-6}$, and appears to be invariant in space and time at a level better than the typical uncertainty of He isotope measurements (Lupton and Evans, 2013); however, the absolute uncertainty of this ratio is worse than 1\% (Blard et al., 2015). Radiogenic He produced directly by the decay of $\mathrm{U}$ and $\mathrm{Th}$ is $100 \%{ }^{4} \mathrm{He}$, but neutrons produced primarily by $(\alpha, \mathrm{n})$

50 reactions as a result of the same radioactive decay processes produce ${ }^{3} \mathrm{He}$ through the reaction ${ }^{6} \mathrm{Li}(\mathrm{n}, \alpha)^{3} \mathrm{He}$ at a rate dependent on the composition of the mineral, primarily its Li content. Minerals such as apatite (Farley et al., 2001) and zircon (Sliwinski et al., 2018) typically have less than $1 \mathrm{ppm} \mathrm{Li}$, which yields an insignificant quantity of ${ }^{3} \mathrm{He}$, although these too could be compromised by adjacent $\mathrm{Li}$-rich minerals such as micas and amphiboles due to the relatively long $\sim 30 \mu \mathrm{m}$ stopping distance of the ${ }^{3} \mathrm{He}$ produced by the ${ }^{6} \mathrm{Li}(\mathrm{n}, \alpha)^{3} \mathrm{He}$ reaction (Farley et al., 2001). Analytical techniques for (U-Th)/He dating often do not

55 even allow the possibility of measuring ${ }^{3} \mathrm{He}$ in the sample, as the isotope is frequently used as a spike on quadrupole mass spectrometers that are not, in any case, capable of resolving small natural abundances of ${ }^{3} \mathrm{He}$ from the ubiquitous HD background. Finally, an isotopic correction for air contamination would have to assume no isotopic fractionation during the trapping process and a well-known laboratory air composition, but the extremely small structures that would be required to irreversibly trap He within the surface layer of minerals would be likely to fractionate the gas isotopically, and the pervasive

60 use of He and other compressed gases in laboratories makes the composition of the laboratory atmosphere variable and difficult to predict without frequent measurement.

Typical analytical procedures for (U-Th)/He dating and other He isotope analyses call for approximately sand-sized particles with dimensions in the range of 50-500 $\mu \mathrm{m}$. There are several reasons for this. The stopping distance of $\alpha$ particles in minerals 
65 is $15-40 \mu \mathrm{m}$, depending on the mineral and the energy of the particle. Because $\alpha$ particles that travel outside of a mineral after emission during $\mathrm{U}$ and $\mathrm{Th}$ decay are lost even as the radioactive parents remain, one must make an alpha ejection correction in the course of (U-Th)/He dating, and the magnitude and uncertainty of this correction becomes very large as the grain size analyzed approaches the ejection lengthscale (Farley et al., 1996). Practically, powders finer than sand-sized are difficult to handle in the vacuum system, so one tends to choose coarser material when possible. It is also simpler to ensure the mineralogical purity of the samples when they are large enough to manipulate easily and observe under a microscope, but not so large that it is impossible to isolate individual crystals or to see inclusions. There are two reasons one might choose to analyze minerals that are finer than sand-sized: in some cases, the grain size of the sample may simply be smaller; in other cases, one might wish to crush a sample to avoid pervasive small inclusions or intergrowths. The latter case is rare; typically, one can isolate mineralogically pure samples that are no smaller than $50 \mu \mathrm{m}$, which is above the size range of concern based on the results of Protin et al. (2016). However, there are many cases in which the material is naturally fine-grained. Examples include polycrystalline iron oxides, which can be dated using the (U-Th)/He and (U-Th)/Ne methods, and which comprise a range of crystallites as small as less than $1 \mu \mathrm{m}$ (Farley and Flowers, 2012; Farley and McKeon, 2015) and interplanetary dust particles, in which ${ }^{3} \mathrm{He}$ is measured as a constant flux proxy, and for which the size range of interest is a few $\mu \mathrm{m}$ to less than $35 \mu \mathrm{m}$ (Farley et al., 1997).

80

The study of Protin et al. (2016) used isotopic deconvolution and sequential crushing in an attempt to quantify the amount of He contamination from laboratory air. Our approach is much simpler: while we sought to confirm in broad terms the results of Protin et al., we do not attempt to quantify the surface area effect that they document. Rather, we accept the premise that contamination from atmospheric He is possible and instead take advantage of pure He gas (200,000 times more concentrated

85 than $\mathrm{He}$ in the atmosphere) to investigate the mechanism of contamination using a coarser size fraction and to arrive at a solution that allows us to avoid the problem in practical situations. While we do not attempt to degas the samples before crushing or to quantify the isotopic composition of the He components, the use of pure He gas during crushing makes these tests very sensitive compared to the concentrations of a few ppm that one would typically find in a laboratory atmosphere.

\section{Methodology}

\section{$90 \quad$ 2.1 Sample Preparation}

We prepared samples in a variety of ways to simulate different laboratory noble gas contamination scenarios. In each experiment, we crushed samples of San Carlos olivine in the presence of different gas mixtures at atmospheric pressure, and in some cases under fluids. Initial sample preparation involved picking inclusion-free San Carlos olivine from working samples in the Caltech Geological and Planetary Sciences mineral collection. The San Carlos olivine standard has a variable but 95 moderate He concentration of less than about $7.5 \times 10^{-12} \mathrm{~mol} \mathrm{~g}^{-1}$, and sometimes much less (Mohopatra and Murty., 2000). We chose the San Carlos standard because its highest recorded He concentration is small compared to the contamination expected 
in a pure He environment based on the Protin et al. (2016) measurements, and indeed is more than 150 times less than the highest concentrations measured in this study, and because inclusion-free crystals are readily available. We treat He concentrations less than $1.5 \times 10^{-11} \mathrm{~mol} \mathrm{~g}^{-1}$, or twice the highest concentration recorded by Mahopatra and Murty (2000), as the background level for this study because of the use of non-degassed olivine in the experiments (see background boxes on Figures 1 and 2).

After initial picking, we separated aliquots of the sample for the different crushing treatments. The crushing device we chose was a standard agate mortar and pestle, which we cleaned extensively between experiments using a scouring pad, water, and isopropyl alcohol. With the exception of crushing performed in the presence of air, for which we simply crushed the samples on the bench in a laboratory in which no compressed gas cylinders are used or stored, we created the gas atmospheres by placing the mortar and pestle in a sealed plastic zipper bag during crushing. The gas was introduced through a small opening in the zipper bag, such that the bag inflated and filled with the gas but was not sealed sufficiently well to increase the pressure significantly about ambient atmospheric pressure.

For the initial set of experiments, we simply took the finest portion of the powder to check for He contamination in the different aliquots. After finding initial evidence of contamination, we sieved the samples at $50 \mu \mathrm{m}$ and measured the finer fraction to confirm that the surface area of the crystals was an important control on the degree of He contamination. Finally, we repeated the initial experiments, and added some additional tests, in order to determine whether crushing itself or fine grain size was

115 the controlling factor on He contamination. Additional experiments included crushing in vacuum and in a He-free atmosphere and then later exposing to the $100 \% \mathrm{He}$ atmosphere, crushing under water in the presence of a $100 \% \mathrm{He}$ atmosphere, and leaching the sample for 20 minutes in concentrated nitric acid after crushing in the presence of a $100 \% \mathrm{He}$ atmosphere. We sieved all samples in the second round to a grain size of 37-50 $\mu \mathrm{m}$ after crushing in order to improve the uniformity of the potentially-contaminated surface area in the measured samples.

\subsection{Mass Spectrometry}

We measured the first round of samples using laser degassing followed by measurement with a Pfeiffer Prisma quadrupole used routinely for (U-Th)/He dating at Caltech (House et al., 2000). Measurements were interspersed with background analyses and standardized using a calibrated ${ }^{4} \mathrm{He}$ reference standard and a ${ }^{3} \mathrm{He}$ spike measured against the samples and the standard. The ${ }^{4} \mathrm{He}$ chamber background was less than $5 \times 10^{-14} \mathrm{~mol}$, the ${ }^{3} \mathrm{He}$ spike was $1.3 \times 10^{-13}$ mol, and the ${ }^{4} \mathrm{He}$ reference standard was $3.2 \times 10^{-13} \mathrm{~mol}$. For this set of experiments, we heated each sample to at least $800{ }^{\circ} \mathrm{C}$ to verify that reversibly adsorbed $\mathrm{He}$, or even $\mathrm{He}$ that could be separated from the sample through step heating, was fully removed. We then heated the samples to about $1500{ }^{\circ} \mathrm{C}$ to fully degas them; any additional $\mathrm{He}$ in these measurements represents irreversibly trapped He. 
https://doi.org/10.5194/gchron-2021-42

Preprint. Discussion started: 11 January 2022

(c) Author(s) 2022. CC BY 4.0 License.

(c) (i)

After verifying that the He trapping was irreversible, as reported by Protin et al. (2016), we conducted the second set of experiments using a single high temperature extraction with a vacuum furnace to allow for larger samples, and we measured the trapped He using an MAP 215-50 mass spectrometer. Measurements were interspersed with background analyses and standardized by bracketing with a calibrated ${ }^{4} \mathrm{He}$-doped air reference standard (“Caltech Air”). Procedural blanks ranged from $1.4 \times 10^{-14}$ to $6.6 \times 10^{-14} \mathrm{~mol}$ and were mostly dependent on the cleanliness of the vacuum furnace. The ${ }^{4} \mathrm{He}$ concentration of the air standard was $3.6 \times 10^{-12}$ mol. Extractions were performed at about $1500^{\circ} \mathrm{C}$ to fully degas the samples.

\section{Results and Discussion}

\subsection{He contamination in crushed samples}

As expected based on the results of Protin et al. (2016), we found significant He contamination in samples crushed in the presence of pure He (Figures 1 and 2, appendix tables S1 and S2). The contamination was retained at surprisingly high temperature, with more than $20 \%$ of the additional He retained even after pumping the samples under ultra-high vacuum for

140 several hours and then heating to more than $800^{\circ} \mathrm{C}$ for ten minutes (Figure 1). Because the crushing was carried out at laboratory temperatures $\left(\sim 21^{\circ} \mathrm{C}\right)$, this result suggests that the trapping of $\mathrm{He}$ is indeed irreversible. He merely adsorbed onto the surface of the crushed olivine would be released after placing the samples under vacuum, and certainly after even mild heating. We suggest two possible reasons for this anomalous irreversible He trapping and retention. One, as suggested by Protin et al. (2016), fine-grained samples may exhibit a "lobster pot" trap for He. This analogy implied that the He is trapped

145 by some mechanism that does not allow it to escape (like a lobster pot, which lobsters can easily enter but then not escape due to the geometry of the trap). Under this analogy, He exposure at any time after the sample was crushed would cause contamination, and naturally fine-grained samples would be subject to contamination from the environment. On the other hand, the violent crushing action itself may cause the He to be trapped, perhaps due to tiny fractures or other structures that open during crushing and then heal or anneal immediately. In this case, the He would only be trapped during crushing, but would

150 not be susceptible to irreversible He contamination after crushing, and naturally fine-grained samples would not be subject to the same contamination. Our second set of experiments was designed to distinguish between these two scenarios. 


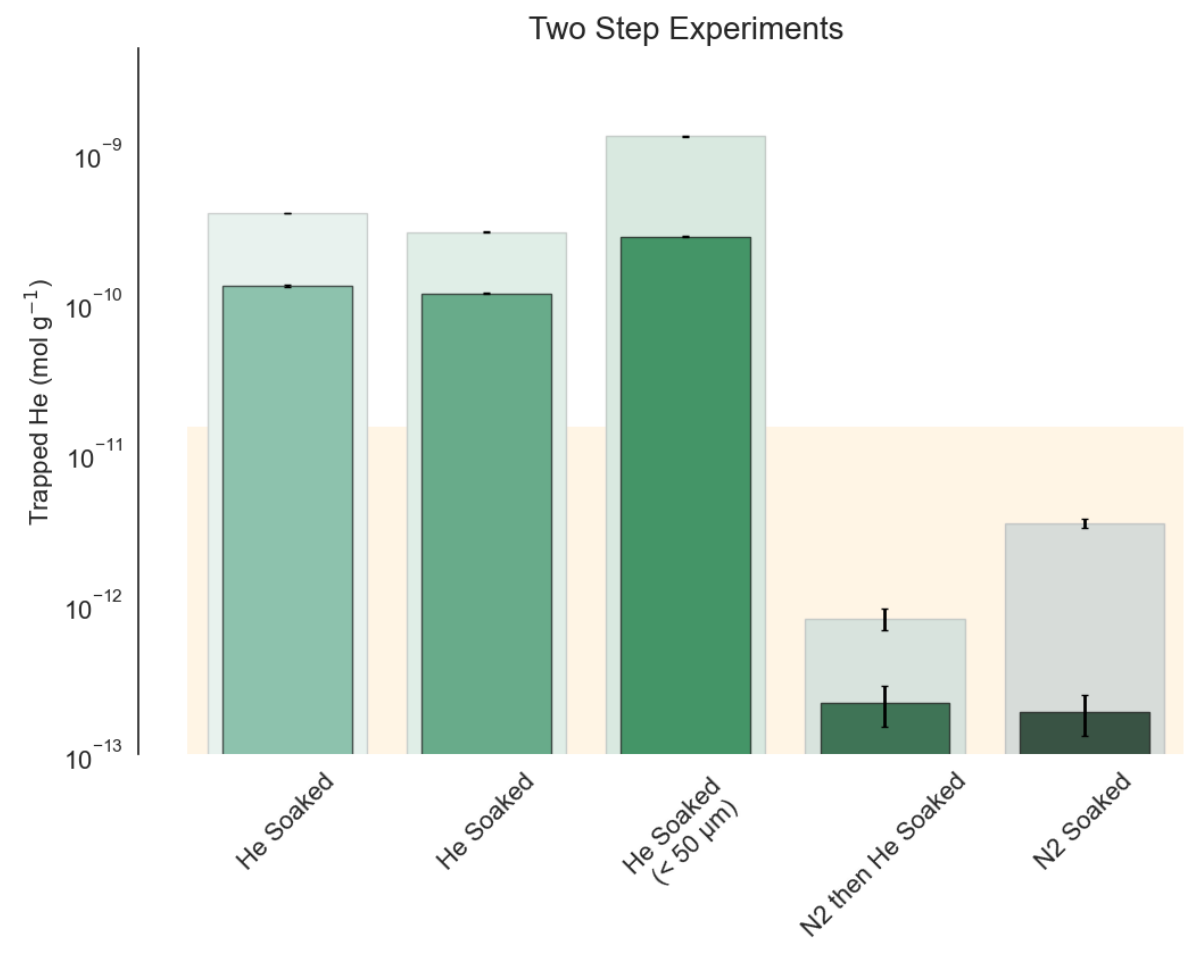

Figure 1: He trapped by crushing process in initial two-heating-step experiments. The orange background rectangle shows the approximate background level of the experiment based on the variable natural He content in San Carlos Olivine (Mohopatra and Murty., 2000; this work). Analytical standard errors shown are 2- $\sigma$ and account for QMS counting statistics, and are small compared to both the natural background and the He enrichment measured in these experiments. The larger pale boxes show the initial lowtemperature $\left(800-900{ }^{\circ} \mathrm{C}\right)$ extractions of each sample, while the foreground boxes show the second high-temperature $\left(1500{ }^{\circ} \mathrm{C}\right)$ extractions. Compared to the samples that were either crushed in pure $\mathrm{N}_{2}$ and then soaked in He or simply crushed in $\mathrm{N}_{2}$ and then analyzed, the samples crushed in the presence of He exhibit a substantial contamination from the He atmosphere during crushing. The aliquot sieved to less than $\mathbf{5 0} \boldsymbol{\mu m}$ shows an even greater He enrichment, consistent with a surface area dependence as shown by Protin et al. (2016).

\subsection{Irreversible He trapping due to crushing, and trapping of other noble gases}

The second set of experiments confirms that the irreversible He trapping occurs during the crushing process rather than a result of the grain size of the samples, or as a result of the fact that they have been crushed. We show dramatic reductions in He contamination, to levels similar to the detection limit of this methodology, in several different scenarios (Figure 2). First, crushing in a neutral atmosphere $\left(\mathrm{N}_{2}\right)$ and then immediately exposing to pure He results in virtually no additional He contamination. This shows that there is not an anomalous He-specific trapping mechanism that remains accessible after the crushing event, but it does not rule out an unexpected irreversible surface trapping mechanism for any gas due to crushing or grain size. In another experiment, however, we crushed in high vacuum using a magnetically-actuated high vacuum crusher, then immediately flooded the vacuum system with pure He. In this case, no other gas was present in the volume of the chamber during crushing, and pure He was the first gas exposed to the sample after crushing, but the experiment still showed far less 
https://doi.org/10.5194/gchron-2021-42

Preprint. Discussion started: 11 January 2022

(c) Author(s) 2022. CC BY 4.0 License.

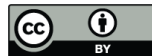

He trapping (about 5\% of the case in which the sample was crushed in the presence of pure He). Finally, we also crushed samples in the presence of a mixture of $25 \%$ each of $\mathrm{He}, \mathrm{Ne}, \mathrm{Ar}$, and $\mathrm{Kr}$. In this case, the sample trapped approximately $25 \%$ as much He as the sample crushed in the presence of pure He. This final experiment, combined with the evidence that pure He is not trapped after either vacuum crushing or crushing in an $\mathrm{N}_{2}$ atmosphere, is consistent with a model in which the sample traps gases present in the atmosphere during crushing according to their volume ratio, rather than trapping He through a mechanism that excludes other gases.

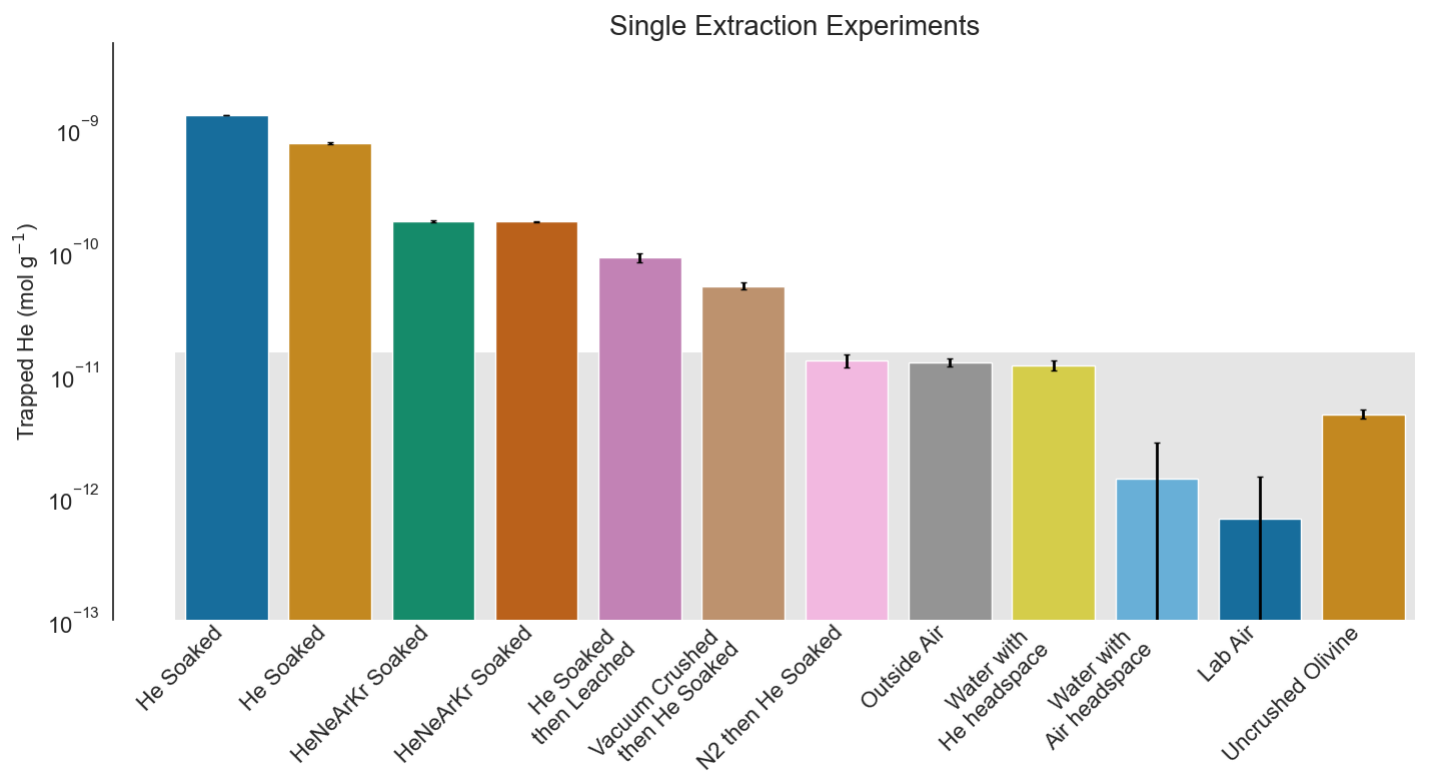

180 Figure 2: He trapped by crushing process in single-step follow-up experiments. The grey background rectangle shows the approximate background level of the experiment based on the variable natural He content in San Carlos Olivine (Mohopatra and Murty., 2000; this work). All samples were sieved to a size range of $37-50 \mu \mathrm{m}$ to reduce variability from sampling. Analytical standard errors shown are 2- $\sigma$ and are small compared to both the natural background and the He enrichment measured in these experiments. The samples crushed in the presence of pure or enriched He show significant enrichments in He. Acid leaching reduces

185 the amount of He contamination, but not to background levels. The sample crushed under vacuum then immediately exposed to pure He also shows a He enrichment, but it is only a few percent of the enrichment seen in the samples exposed to He during crushing. Samples crushed in a neutral atmosphere and then exposed to He, and the sample crushed under water with a pure He atmosphere, are indistinguishable from background.

\subsection{Mechanism of trapping during crushing}

190 The mechanism of trapping during crushing is a matter of speculation, but it is important in that it is clear from our results and from those of Protin et al. (2016) that the trapping is irreversible. The trapping appears to apply to heavier noble gases, meaning that it is not enabled by a mechanism dependent on the unusual mobility and small size of He. It also appears to cease shortly after the physical impact that causes it to occur, as evidenced by the experiments showing minimal contamination of sample crushed in a He-free atmosphere or under vacuum and then later exposed to pure He. Therefore, we consider that the most likely mechanism is that microfractures form during crushing and then close or anneal shortly thereafter. This mechanism 
https://doi.org/10.5194/gchron-2021-42

Preprint. Discussion started: 11 January 2022

(c) Author(s) 2022. CC BY 4.0 License.

(c) (i)
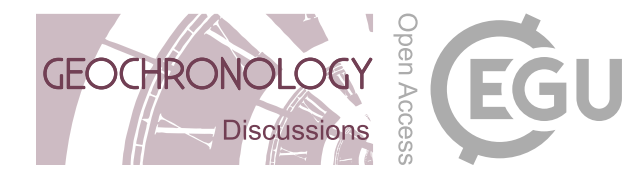

would be consistent with the findings presented here and would also suggest that naturally fine-grained samples are not subject to the same phenomenon.

\subsection{Implications for experimentalists}

While potentially troublesome for experiments that require crushing of low-He samples to a very fine grain size in the laboratory, these results are not nearly as concerning as the possibility that all fine-grained samples trap He, or even the possibility that crushed samples might trap He at any point after crushing. Because the problem is restricted to the time of crushing itself, we explored several solutions that exclude He from this part of the sample preparation. As mentioned above, crushing in a neutral $\left(\mathrm{N}_{2}\right)$ atmosphere then exposing to He did not result in significant contamination, so using a neutral atmosphere such as $\mathrm{N}_{2}$, which is relatively cheap as both a compressed gas or a product of liquid nitrogen boiling, is a solution to the problem (Figure 2). Indeed, in most cases of typical He concentrations in samples, crushing in air (which is only 5 ppm $\mathrm{He}$ ) and taking care to avoid unusually concentrated or isotopically fractionated sources of $\mathrm{He}$ in the laboratory is adequate.

The other solutions we explored were crushing under water and crushing then acid leaching the sample. Leaching the sample in concentrated nitric acid for twenty minutes removed about $45 \%$ of the mass of the 37-50 $\mu \mathrm{m}$ fraction, but only removed about $90 \%$ of the He (Figure 2). While this is a dramatic improvement and shows that trapping occurs mostly on the outer edges of the fragments created during crushing, it is not as effective as simply avoiding He through crushing in a neutral atmosphere. It is also not as effective as crushing under water, which may in many cases be the simplest solution available. He solubility in water is quite low compared to other gases (Weiss, 1970), so working under water is a good way to exclude He, and crushing under water is often preferable anyway because it helps prevent sample loss. For this test, we flooded a bag with

215 pure He in the same way as the experiments showing dramatic increases in sample He concentration during crushing, but also filled the mortar with a $\sim 1 \mathrm{~cm}$ layer of tap water before crushing the sample. The level of He contamination was below the detection limit of this methodology and similar to the sample crushed in air despite the presence of 200,000 times the partial pressure of $\mathrm{He}$ in the atmosphere just above the water layer (Figure 2).

220 In addition to the imperative to avoid unwanted sample contamination, the irreversible trapping mechanism we observe may actually be useful for applications in which trapping exotic noble gas mixtures in minerals would be desirable, such as mineral standard preparation or isotopic spiking in environments such as on planetary bodies. The scope of the current work does not explore the degree or variability of isotopic fractionation during trapping or the extent to which the degree of contamination could be controlled by different crushing techniques or more careful size separation, both of which would be critical for such applications. 


\section{Modeling of impact of He contamination for thermochronology}

\subsection{Model description}

In order to conceptualize the observed phenomena and to make predictions about the effect of anomalous irreversible He trapping on mineral samples used for geochronology, we constructed a simple geometric model to represent one physical explanation consistent with our observations. In this model, presented in the appendix in a Jupyter notebook, the amount of He contamination due to trapping decreases exponentially from the surface of the crystal. Crystals are modeled as a sphere, with He contamination entering from the outer surface. The crystal is approximated as spherical shells of $1 \mu \mathrm{m}$ thickness, with a per-unit-volume He contamination exponential rate constant of $0.29 \mu \mathrm{m}^{-1}$, which is based on the $\sim 90 \%$ of contamination removed by leaching $\sim 45 \%$ of the mass of the $37-50 \mu \mathrm{m}$ samples used here, assuming that the exponential model is correct.

235 For the purpose of comparison to He concentrations in geo/thermochronology, we simulate the radiogenic ingrowth of He in apatite crystals of several age and $U$ concentrations. Alpha ejection is ignored, so there is no difference between He from $U$ and Th decay, and so only $U$ is considered for the sake of model simplicity. The same principles can be applied to radiogenic ${ }^{4} \mathrm{He}$ and cosmogenic ${ }^{3} \mathrm{He}$ in other minerals, with the caveat that ${ }^{3} \mathrm{He}$ contamination should be scaled down by the ${ }^{3} \mathrm{He} /{ }^{4} \mathrm{He}$ ratio in the atmosphere, which is $1.39 \times 10^{-6}$ if the contaminant is atmospheric He.

This model allows us to scale the degree of contamination to different grain sizes, and to compare the atmospheric He contamination to the radiogenic He concentration of minerals of different ages and $U$ concentrations. The reference point used for these scaling calculations is a crystal with a diameter of $45 \mu \mathrm{m}$ (radius $22.5 \mu \mathrm{m}$ ), in the middle of the sieve range used for the second round of experiments, and an amount of He contamination equal to $1.37 \times 10^{-14} \mathrm{~mol} \mathrm{~g}^{-1}$, which represents two times the worst contamination observed in our pure He-soaked experiments $\left(1.31 \times 10^{-9} \mathrm{~mol} \mathrm{~g}^{-1}\right)$, scaled down to $5.24 \mathrm{ppm}$ (the atmospheric concentration of $\mathrm{He}$ ), both to present a conservative model and to account for the possibility of slightly elevated ${ }^{4} \mathrm{He}$ in laboratory environments due to the use of concentrated $\mathrm{He}$ in laboratory processes.

The concentration of the outer shell of the $r=22.5$ model is calculated by creating a series of shells assuming spherical geometry, meaning that the volumes are simply given by

$$
V_{n}=\frac{4}{3}\left(r_{n}^{3}-r_{n+1}^{3}\right)
$$

where $V_{n}$ is the volume of the shell beginning at $\mathrm{r}_{\mathrm{n}}$, where $\mathrm{r}_{\mathrm{n}}$ is the outer radius of the nth shell, counting from the outside of the crystal inward, and $r_{n+1}$ is the inner radius of shell $n$, or the outer radius of shell $n+1$. The fractional volume of the shell is then given by

$$
V_{\mathrm{n}, \text { frac }}=V_{n} / \sum_{i=0}^{r_{0} / a} V_{i}
$$


where $V_{n, f r a c}$ is the fractional volume of shell $\mathrm{n}, V_{n}$ is the volume of shell $\mathrm{n}, \mathrm{r}_{0}$ is the radius of the crystal, and a is the width of shells used in the model. Note that $\mathrm{a}=1 \mu \mathrm{m}$ except for crystals $<10 \mu \mathrm{m}$ in radius, in which case we split the crystal into ten shells. We then use this fractional volume to weight the exponential fit of the He contamination for each shell by volume, an effect which becomes more significant for smaller crystals in which the outer shell volumes differ dramatically. The relative per-unit-volume He contamination is given by

$$
[\mathrm{He}]_{\mathrm{rel}}^{n}=e^{0.29\left(r_{n}-r_{0}\right)}
$$

where $[\mathrm{He}]_{\mathrm{rel}}^{n}$ is the relative He contamination of shell $n$. Note that for the outer shell $(n=0), r_{n}=r$, so the He contamination is defined relative to the outer shell. Based on our measurements, we assume that the total concentration of He in the crystal will be $1.37 \times 10^{-14} \mathrm{~mol} \mathrm{~g}^{-1}$, then we determine the fraction of this that is present in the outer shell. We used olivine for the experiments as described in Section 2.1 but we use apatite for these calculations in order to demonstrate the relative significance of the contamination in the mineral most commonly used for He measurements. The volume concentration of $\mathrm{He}$ contamination in the outermost shell is given by

$$
[\mathrm{He}]_{\text {outer }}=[\mathrm{He}]_{\mathrm{T}} \rho_{c} V_{0, \text { frac }} \frac{[\mathrm{He}]_{\mathrm{rel}}^{0}}{\sum_{i=0}^{r_{0} / a}[\mathrm{He}]_{\mathrm{rel}}^{i}}
$$

where $[\mathrm{He}]_{\mathrm{T}}=1.37 \times 10^{-14} \mathrm{~mol} \mathrm{~g}^{-1}$ and $\rho_{c}$ is the density of the crystal. We note that while the density of different minerals is small compared to the likely variability of the cracking effect, we are also assuming that the geometric model of cracking applies similarly to different crystal systems. The goal of this work is to show the order of magnitude of the problem and suggest ways to avoid it when it may be significant, but if this model were to be used quantitatively, more careful investigation of the behavior of individual crystal systems might be warranted.

275 We then take the volume concentration of $\mathrm{He}$ in the outer shell $[\mathrm{He}]_{\text {outer }}$ and apply it to the outer shell of modeled crystals of different sizes in order to calculate the relative contamination in each. For each test radius $r_{\text {test, }}$ we break the crystal up into either $r_{\text {test }} /(1 \mu \mathrm{m})$ shells of $\mathrm{a}=1 \mu \mathrm{m}$ width or, in the case of crystals $<10 \mu \mathrm{m}$ in radius, 10 shells of $\mathrm{a}=r_{\text {test }} / 10$ width. We then calculate relative He concentrations in each shell in the same manner described above, then calculate the He concentration in each shell $\mathrm{n}$ using the equation

$$
[\mathrm{He}]^{n}=[\mathrm{He}]_{\text {outer }}[\mathrm{He}]_{\mathrm{rel}}^{n} V_{n}
$$

in which the outer shell concentration will simply be the value calculated for the $45 \mu \mathrm{m}$ crystal, weighted according to the actual volume of the test crystal outer shell, and the inner shells will be weighted by both volume and the exponentially decreasing cracking frequently defined above. The total amount of He contamination is then given by simply summing over all the shells $n$

$$
[\mathrm{He}]_{\mathrm{total}}=\sum_{i=o}^{r_{\text {test }} / a}[\mathrm{He}]^{i}
$$


We then compare the total contamination $[\mathrm{He}]_{\text {total }}$ for a given crushed crystal of size $\mathrm{r}_{\text {test }}$ to predicted He concentrations for crystals of the same volume and a given age and $U$ concentration to show for which (U-Th)/He samples the effect might be important. The same logic can be applied to cosmogenic He or other samples by simply considering the He concentrations that result from these calculations and the dramatically lower ${ }^{3} \mathrm{He}$ concentration (the ${ }^{3} \mathrm{He} /{ }^{4} \mathrm{He}$ of atmosphere, $\mathrm{R}_{\mathrm{a}}=1.39 \times 10^{-6}$ ).

\subsection{Model results for different crystal sizes and radiogenic He concentrations}

Assuming no loss to diffusion or ejection of alpha particles during radioactive decay, radiogenic He grows into crystals at a rate proportional to the concentration of ${ }^{238} \mathrm{U},{ }^{235} \mathrm{U},{ }^{232} \mathrm{Th}$, and other minor nuclides that decay by alpha emission. The model allows us to compare the He contamination observed here to radiogenic He concentrations in minerals of a given $\mathrm{U}$ concentration (the model applies to other alpha emitters, the concentrations of which can simply be scaled according to alpha activity) and age, and to adjust the level of contamination according to a geometric model of He trapping that assumes exponential decay of the degree of He contamination with depth into the crystal. This simple model reflects just one hypothesis for the nature of He trapping that is consistent with our observations, but it provides an order-of-magnitude tool for determining under which situations even the relatively simple precautions suggested in Section 3.4 need be considered.

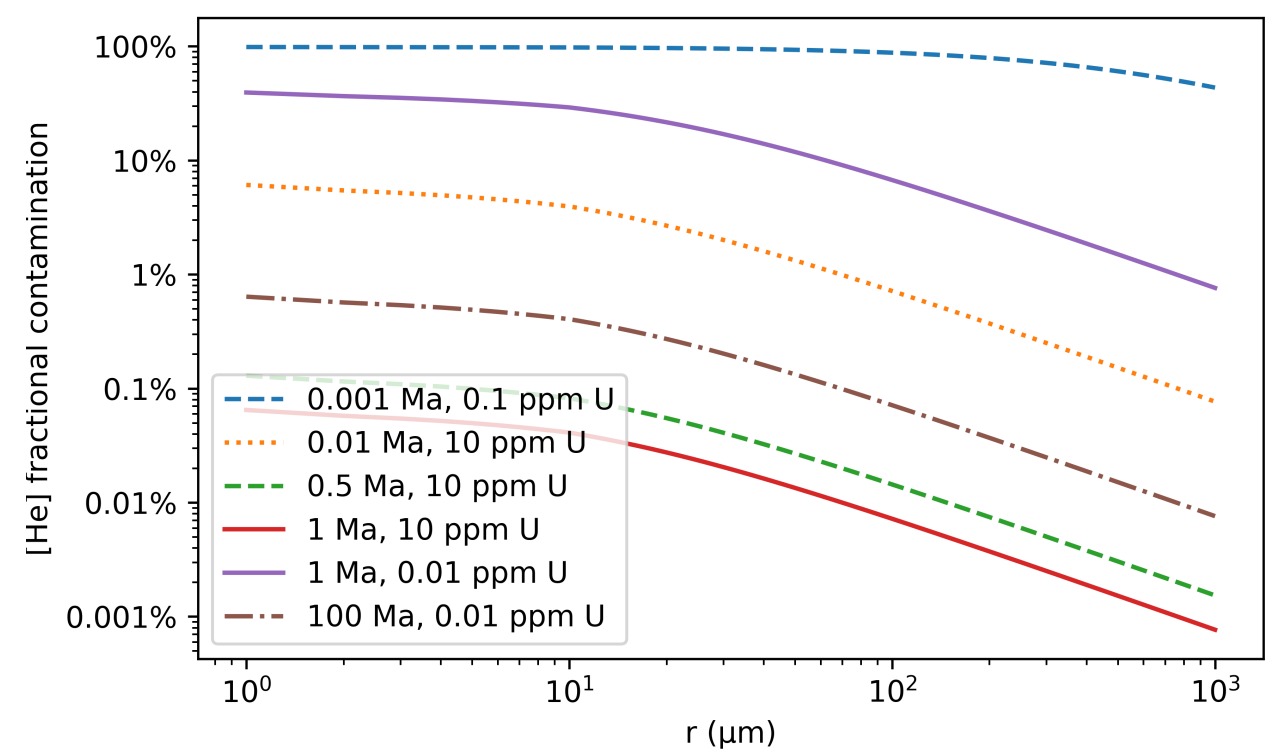

Figure 3: Modeled He contamination as a fraction of total He (radiogenic and contamination) due to cracking in crystal fragments of a certain size, age, and $U$ concentration. The spherical model used here is adequate as an approximation for most crystals, but the model code can be modified to account for extreme geometries. Only very young or low-U samples will exhibit a problematic degree of He contamination compared to radiogenic He ingrowth. 
https://doi.org/10.5194/gchron-2021-42

Preprint. Discussion started: 11 January 2022

(c) Author(s) 2022. CC BY 4.0 License.

(c) (i)

A selection of model results is presented in Figure 3. The model results show that while He contamination represents a very high fraction $(>20 \%)$ of the radiogenic He in small crystals $(<45 \mu \mathrm{m})$ of moderate age and very low $\mathrm{U}$ concentration $(1 \mathrm{Ma}$ and $10 \mathrm{ppb}$ ) or moderate $\mathrm{U}$ concentration and extremely young age (10 ka and $1 \mathrm{ppm})$, the fraction quickly becomes small $(<5 \%)$ for samples in the range of (U-Th)/He applications (1 ppm U, $1 \mathrm{Ma}$, at least $10 \mu \mathrm{m}$ radius) and is insignificant for typical samples (for example, $<0.2 \%$ for a $10 \mathrm{ppm} \mathrm{U,1} \mathrm{Ma} \mathrm{mineral} \mathrm{with} \mathrm{a} \mathrm{radius} \mathrm{of} 63 \mu \mathrm{m}$ ). This means that while rock crushing for separation of accessory minerals like apatite is typically performed using techniques like disk milling that would be difficult to adapt in a way that keeps the mineral under water, the He contamination problem is nonetheless insignificant for typical samples used for (U-Th)/He. Only exceptional samples with very small, young, and low U concentrations will require special care to avoid He contamination during processing.

\section{Conclusions}

These results confirm the experimental data of Protin et al. (2016). However, we find overwhelming evidence that the irreversible trapping of He occurs during the crushing process rather than as a result of the grain size of the sample. The effect will still scale with grain surface area, as it appears that the trapping happens in the outer layer of the crushed fragments and can be mostly removed by acid leaching. However, one must only avoid He during crushing in order to avoid contamination of geological samples. Naturally fine-grained samples and samples crushed in the absence of He do not exhibit the same effect. We hypothesize that the crushing process opens small damage zones that are quickly healed or annealed, and that can only irreversibly trap gas that is exposed to the sample before the healing occurs. Our experiments demonstrate that this process is complete within a few minutes, and it seems likely that the entire process occurs on the sub- $\mu$ s timescale of the propagation of pressure waves through the minerals. The simplest means of avoiding contamination is to crush samples under water or other liquid, so we recommend crushing under water for all low-He samples that must be crushed to a fine powder in the laboratory. This solution will work for any mineral, and for both isotopes of He and for other noble gas species. Samples of the grain size commonly used for most measurements, such as (U-Th)/He dating, and naturally fine-grained samples are not susceptible to this problem.

\section{Data and code availability}

330 The code and data used in this study are included in the appendix.

\section{Author contributions}

SC, HM, FH, and KF contributed to conceptualization of the study. SC and HM designed and executed the experiments. KF advised on laboratory analyses and experimental design. SC, HM, FH, and KF participated in discussion about trapping 
https://doi.org/10.5194/gchron-2021-42

Preprint. Discussion started: 11 January 2022

(c) Author(s) 2022. CC BY 4.0 License.

(c) (i)

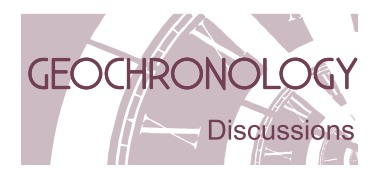

mechanism and designed adjustments to common laboratory procedures. SC created the software model, prepared figures, and

prepared the original draft. HM conducted model validation. SC, HM, FH, and KF contributed to editing of the manuscript.

\section{Competing interests}

The authors declare no competing interests.

\section{References}

Blard, P.-H., Puchol, N., and Farley, K.A.: Constraints on the loss of matrix-sited helium during vacuum crushing of mafic phenocrysts, Geochim. Cosmochim. Ac., 72, 3788-3803, doi:10.1016/j.gca.2008.05.044, 2008.

Blard, P.-H., Balco, G., Burnard, P.G., Farley, K.A., Fenton, C.R., Friedrich, R., Jull, A.J.T., Niedermann, S., Pik, R., Schaefer, J.M., Scott, E.M., Shuster, D.L., Stuart, F.M., Stute, M., Tibari, B., Winckler, G., Zimmerman, L.: An inter-laboratory comparison of cosmogenic ${ }^{3} \mathrm{He}$ and radiogenic ${ }^{4} \mathrm{He}$ in the CRONUS-P pyroxene standard, Quat. Geochron., 26, 11-19, doi:10.1016/j.quageo.2014.08.004, 2015.

345 Farley, K.A., Wolf, R.A., and Silver, L.T.: The effects of long alpha-stopping distances on (U-Th)/He ages, Geochim. Cosmochim. Ac., 60, 4223-4229, doi:10.1016/S0016-7037(96)00193-7, 1996.

Farley, K.A., Love, S.G., and Patterson, D.B.: Atmospheric entry heating and helium retentivity of interplanetary dust particles, Geochim. Cosmochim. Ac., 61, 2309-2316, doi:S0016-7037(97)00068-9, 1997.

Farley, K.A., Cerling, T.E., and Fitzgerald, P.G.: Cosmogenic ${ }^{3} \mathrm{He}$ in igneous and fossil tooth enamel fluorapatite, Earth Planet. 350 Sci. Lett., 185, 7-14, doi: 10.1016/S0012-821X(00)00360-5, 2001.

Farley, K.A. and Flowers, R.M.: (U-Th)/Ne and multidomain (U-Th)/He systematics of a hydrothermal hematite from eastern Grand Canyon, Earth Planet. Sci. Lett., 359-360, 131-140, doi:10.1016/j.epsl.2012.10.010, 2012.

Farley, K.A. and McKeon, R.: Radiometric dating and temperature history of banded iron formation-associated hematite, Gogebic iron range, Michigan, USA, Geology, 43, 1083-1086, doi:10.1130/G37190.1, 2015.

355 House, M.A., Farley, K.A., and Stockli, D.: Helium chronometry of apatite and titanite using Nd-YAG laser heating, Earth Planet. Sci. Lett., 183, 365-368, doi:10.1016/S0012-821X(00)00286-7, 2000.

Lupon, J., and Evans, L.: Changes in the atmospheric helium isotope ratio over the past 40 years, Geophys. Res. Lett., 40, 6271-6275, doi:10.1002/2013GL057681, 2013.

Mohopatra, R.K., and Murty, S.V.S.: Search for the mantle nitrogen in the ultramafic xenoliths from San Carlos, Arizona, 360 Chem. Geo., 164, 305-320, doi:10.1016/S0009-2541(99)00148-5, 2000.

Protin, M., Blard, P-H, Marrocchi, Y., and Mathon, F.: Irreversible Adsorption of Atmospheric Helium on Olivine: A Lobster Pot Analogy, Geochim. Cosmochim. Ac., 179, 76-88, doi:10.1016/j.gca.2016.01.032, 2016. 
https://doi.org/10.5194/gchron-2021-42

Preprint. Discussion started: 11 January 2022

(C) Author(s) 2022. CC BY 4.0 License.

(c) (i)

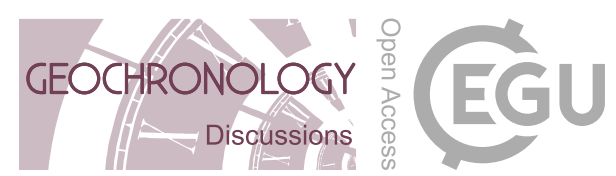

Weiss, R.F.: Solubility of Helium and Neon in Water and Seawater, J Chem. Eng. Data, 16, 235-241, doi:10.1021/je60049a019, 1970. 